\title{
Loneliness, Depression, and Anxiety Experienced by the Israeli Population During the First COVID-19 Lockdown: A Cross-sectional Survey
}

\author{
Jason Brafman, B.A. ${ }^{1}$, Robert Lubin, Psy.D. ${ }^{1 *}$, Revital Naor-Ziv, Ph.D. ${ }^{2}$, Sarah \\ Rosenberg, M.A. ${ }^{3}$, and Tzvi Dwolatzky, M.B.B.Ch. ${ }^{1,4}$ \\ ${ }^{1}$ The Ruth $\mathcal{O}^{\circ}$ Bruce Rappaport Faculty of Medicine, Technion-Israel Institute of Technology, Haifa, \\ Israel; ${ }^{2}$ Department of Criminology, Bar-Ilan University, Ramat Gan, Israel; ${ }^{3}$ Keep Olim, Society for the \\ Advancement of Immigrants to Israel, Jerusalem, Israel; and ${ }^{4}$ Geriatric Unit, Rambam Health Care \\ Campus, Haifa, Israel
}

\section{INTRODUCTION}

The presence of loneliness, depression, and anxiety is known to be associated with increased overall morbidity. ${ }^{1,2}$ These conditions may occur as individual syndromes or in combination. There is a clear need to recognize these conditions when they occur and to provide patients with appropriate care and support. From a public health perspective, it is important to evaluate both the prevalence and the epidemiological risk factors associated with these syndromes. For example, approximately $50 \%$ of mental health disorders have been shown to begin during the mid-teenage years. ${ }^{3}$ As such, mental health screen- ing should specifically target the younger population since, while these disorders frequently manifest early on in adolescence, intervention and treatment are not usually initiated until years later. ${ }^{4}$ At times of stress and crisis, mental health disorders in younger individuals are often more pronounced. This may reflect an exacerbation of pre-existing depression or anxiety, may manifest the transformation of a preclinical mental disorder into a symptomatic one, or may represent a risk factor for the development of a mental health condition de novo.

\begin{abstract}
Abbreviations: COVID-19, coronavirus 2019; PHQ-4, Four-item Patient Health Questionnaire.
Citation: Brafman J, Lubin R, Naor-Ziv R, Rosenberg S, Dwolatzky T. Loneliness, Depression, and Anxiety Experienced by the Israeli Population During the First COVID-19 Lockdown: A Cross-sectional Survey. Rambam Maimonides Med J 2021;12 (4):e0030. doi:10.5041/RMMJ.10449
\end{abstract}

Copyright: (C) 2021 Brafman et al. This is an open-access article. All its content, except where otherwise noted, is distributed under the terms of the Creative Commons Attribution License (http://creativecommons.org/licenses/by/3.0), which permits unrestricted use, distribution, and reproduction in any medium, provided the original work is properly cited.

Conflict of interest: No potential conflict of interest relevant to this article was reported.

* To whom correspondence should be addressed. E-mail: rlubin@technion.ac.il 
The coronavirus 2019 (COVID-19) pandemic is certainly the greatest challenge facing countries, populations, economies, and health care services in the last 20 years. The stresses resulting from this pandemic place an additional burden on the mental health of people of all ages. ${ }^{4-6}$ Traditionally, government health funding has not emphasized planning for the mental health consequences of such major public health challenges. ${ }^{7}$ Generally, mental health resources are scarce, with minimal emphasis on mental health screening, and services for populations who are at higher risk for mental health morbidity are inadequate. Many studies have already noted the important impact that COVID-19 has had on mental health. ${ }^{8-13}$

This study sought to evaluate the differences in the prevalence of self-reported symptoms of depression, anxiety, and loneliness between younger and older generations at the time of the COVID-19 pandemic. Since the younger generation is generally less accustomed to facing and dealing with adversity and illness, we hypothesized that adolescents and younger adults would have a higher prevalence of depression, anxiety, and loneliness as compared to the older generations. It must be emphasized that this survey was conducted during the first COVID-19 lockdown that occurred in Israel from mid-March 2020 to early-May 2020. This was a time when businesses were closed, individuals and families were isolated at home with very limited social contact, and feelings of fear and panic were fueled by the electronic media.

\section{METHODS}

Our study included participants of the age groups representing Generation Z (16-23 years), Millennials (24-39 years), Generation X (40-55 years), Baby Boomers/Maturists ( $>56$ years). The survey was distributed to students and faculty of both the Ruth \& Bruce Rappaport Faculty of Medicine at the Technion-Israel Institute of Technology and of BarIlan University, and was posted on social media sites such as Facebook and WhatsApp. The survey was available in Hebrew, English, and Spanish. A notification was sent to those who expressed an interest in completing the survey confirming that their responses would be confidential, and an "opt-out" option was available for those who did not want their responses used for research. The study was approved by the Ethics Review Board of Bar-Ilan University (Ref. 21 May 2020), and the researchers had access only to anonymized data.
The Four-item Patient Health Questionnaire (PHQ-4), a brief screening tool for depression and anxiety, ${ }^{14}$ was made available to respondents who had the option of completing it in Hebrew, English, or Spanish. The four items are four questions regarding symptoms of anxiety or depression or both. The PHQ-4 was chosen for screening for depression and/or anxiety based on its attributes of high sensitivity and specificity as well as brevity. ${ }^{14}$ The sum of the four items of the PHQ-4 yields a composite score ranging from o to a maximum of 12 . For the purpose of our study a score of 2 or less on the PHQ-4 was considered to be negative, while a score of 3 or more was defined as a positive screen for depression/anxiety. Participants were also asked to complete other self-reporting measurements and to provide demographical information as well as answer a screening question about feelings of loneliness. The responses on screening for loneliness were "never," "sometimes," "more than half the time," or "almost every day." The wording was slightly changed from the classic PHQ-4 for a more appropriate grammatical fit to a context that applied only during the COVID19 lockdown in Israel from March to May 2020 as well as for cognitive ergonomics. An identical translation was done previously by Lowe et al. ${ }^{15}$ and Zhao et al. ${ }^{16}$ Also, the original language of the survey was Spanish; as such, our word choice fit better with a direct translation from the Spanish, maintaining consistency between languages. The Hebrew translation was likewise grammatically and syntactically consistent. A response of "more than half the time" or "almost every day" was defined as a positive screen for loneliness, while a response of "never" or "sometimes" was defined as negative.

As mentioned, individuals constituting Generation $\mathrm{Z}$ are at increased risk for mental health issues, and as such may be less resilient in coping with the stresses of challenging global events such as the current pandemic. Based on this premise, we designated a cutoff of those born in 1997 and later in order to distinguish those constituting Generation Z from older participants.

\section{RESULTS}

A total of 665 individuals responded to the survey, of which 653 included their age in their response and were included in the data analysis (range, 16-85 years; mean $=38$ ). The age distribution of the study group is presented in Figure 1. Of the 653 responses included in the analysis, 406 responded in Hebrew, 195 in English, and 52 in Spanish. 


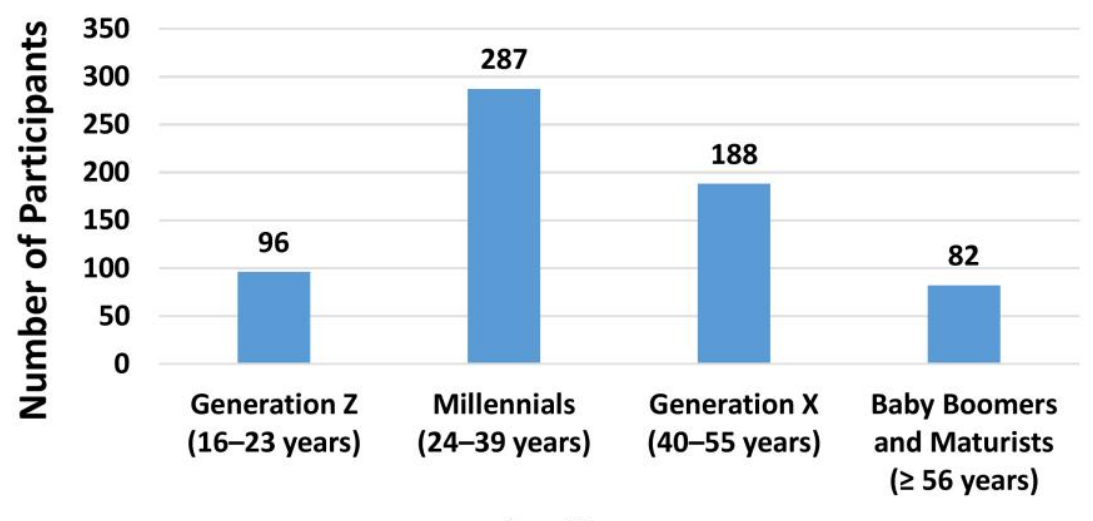

Age Years

Figure 1. Age Distribution of Respondents $(n=653)$.

Relevant elements of the survey for analysis were: age, and if the respondent had experienced "loneliness," "little interest or pleasure in doing things," "weariness, depression, or hopelessness," "nervousness or tension," and "inability to stop or control worrying thoughts." The last four aforementioned elements constitute the PHQ-4. The four possible answers for the PHQ-4 and loneliness were "never," "sometimes," "more than half the time," or "almost every day," scored as 0, 1, 2, or 3, respectively. Results are presented in Table 1 . The cutoff for depression, anxiety, and loneliness was "more than half the time" or worse. We found that selfreported loneliness was highest among Generation Z. Interestingly, self-reported depression and anxiety was almost the same for Generation $\mathrm{Z}$ and Mil- lennials ( $77 \%$ and $78 \%$, respectively), though it was also reported by Generation X and Baby Boomers.

Statistical analysis using the one-sided ANOVA test revealed statistical significance for loneliness $(F$ ratio value: $9.42961, P$ value: $<0.00001)$, but none for the PHQ-4 depression and anxiety data ( $F$ ratio value: $2.43138, P$ value: 0.064084 ). Post hoc Tukey HSD testing also yielded significant differences for loneliness as shown in Table 2.

\section{DISCUSSION}

In this self-reported survey, we found that younger respondents experienced a greater incidence of feelings of loneliness at the time of the first lockdown in Israel during the COVID-19 pandemic as

Table 1. Responses to the Survey with Regard to Loneliness and the PHQ-4 According to Age Group.

\begin{tabular}{|c|c|c|c|c|}
\hline Survey & $\begin{array}{c}\text { Generation } Z \\
(16-23 \text { years }) \\
(n=96)\end{array}$ & $\begin{array}{c}\text { Millennials } \\
(24-39 \text { years }) \\
(n=287)\end{array}$ & $\begin{array}{c}\text { Generation } X \\
(40-55 \text { years }) \\
(n=188)\end{array}$ & $\begin{array}{l}\text { Baby Boomers and } \\
\text { Maturists }(\geq 56 \text { years }) \\
(n=82)\end{array}$ \\
\hline \multicolumn{5}{|l|}{ Self-reported Loneliness } \\
\hline Never, $n(\%)$ & $33(34.3)$ & $127(44.2)$ & $118(62.8)$ & $50(61.0)$ \\
\hline Sometimes, $n$ (\%) & $31(32.3)$ & $87(30.3)$ & $42(22.3)$ & $27(32.9)$ \\
\hline More than half the time, $n(\%)$ & $13(13.5)$ & $35(12.2)$ & $18(9.6)$ & $2(2.4)$ \\
\hline Almost every day, $n(\%)$ & $19(19.8)$ & $38(13.2)$ & $10(5.3)$ & $3(3.7)$ \\
\hline \multicolumn{5}{|l|}{ Self-reported PHQ-4 } \\
\hline Negative (score 0-2), $n(\%)$ & $22(23.0)$ & $63(22.0)$ & $58(30.9)$ & $27(32.9)$ \\
\hline Positive (score $\geq 3$ ), $n(\%)$ & $74(77.0)$ & $224(78.0)$ & $130(69.1)$ & $55(67.1)$ \\
\hline
\end{tabular}

PHQ-4, 4-Item Patient Health Questionnaire. 
Table 2. Post Hoc Tukey HSD for Loneliness Results.*

\begin{tabular}{|lcc|}
\hline Pairwise Comparisons & Q Value & $P$ Value \\
\hline Generation Z : Millennials & 2.22 & 0.40 \\
Generation Z : Generation X & 5.19 & 0.001 \\
Generation Z : Baby Boomers/Maturists & 7.66 & $<0.001$ \\
Millennials : Generation X & 2.97 & 0.15 \\
Millennials : Baby Boomers/Maturists & 5.44 & $<0.001$ \\
Generation X : Baby Boomers/Maturists & 2.47 & 0.30 \\
\hline
\end{tabular}

compared to older respondents. While there was a trend for experiencing a greater feeling of depression and/or anxiety in these younger respondents, this difference was not significant.

Our age cutoff levels were chosen based on the definitions of generational cohorts, namely Generation Z, Millennials, Generation X, Baby Boomers, and Maturists. Our premise was that younger individuals were fitter, healthier, and more adaptive to change and would thus be more able to adjust to the stress of a pandemic/lockdown. Although we do recognize the possibility of unrecognized mental health issues in adolescents and young adults as mentioned earlier, the age group constituting Generation $\mathrm{Z}$ and Millennials generally is healthier and less likely to experience major physical illness or disability as compared to the older population. As such, we may expect these younger generations to be more resilient at the time of social stress and upheaval. Our finding of a greater feeling of loneliness in the younger generational cohorts is thus interesting. While we have not identified similar published studies looking at the generational effects of loneliness and mental health at the time of the COVID19 pandemic, our results conform with recent reports in the media. ${ }^{17,18}$ This finding raises important issues that should be addressed, such as disrupted rhythms of life and the social effects of lockdown.

There are several limitations to this study. The survey was distributed via universities, making individuals without a connection to a university less likely to have received an invitation to participate in the survey. In addition, although we received a good number of responses to the survey, a larger sample size that is more representative of the Israeli population would clearly improve the generalizability of our findings. The survey was available in English,
Hebrew, and Spanish, and we did not compare responses based on language. Clearly, those of different backgrounds, particularly immigrants compared to native Israelis, may be more prone to psychological distress and loneliness as they try to adapt to a new environment at the time of a pandemic. While the survey was conducted specifically in the narrow time frame of the first COVID-19 lockdown in Israel, conducting the survey over a longer time period may have provided a greater insight into the subsequent development of loneliness, depression, or anxiety. Our finding that self-reported loneliness was highest in Generation Z should be regarded with caution since the number of respondents in this group was relatively small compared to the other groups. Also, the feeling of loneliness in Generation $\mathrm{Z}$ may be related to the fact that they are generally less accustomed to facing and dealing with adversity and other factors, and thus the association with the COVID-19 lockdown may not be causative.

Our findings are interesting and raise important issues. Adolescents and young adults are more prone to loneliness, and the association of loneliness and mental health symptomatology, especially anxiety and depression, with the ongoing COVID-19 pandemic should be further investigated. In fact, the symptoms of psychological stress were high in all age groups. These symptoms should be recognized and treated on a personal level, and appropriate public health measures should be implemented. With the continuing pandemic worldwide, the longterm effects of limitations such as social isolation should be carefully assessed, mapping of loneliness and psychological stress should include all age groups, and health care organizations and policy makers should initiate widespread policies of support and stress management. 


\section{REFERENCES}

1. House JS, Landis KR, Umberson D. Social relationships and health. Science 1988;241:540-5. CrossRef

2. Pratt LA, Druss BG, Manderscheid RW, Walker ER. Excess mortality due to depression and anxiety in the United States: results from a nationally representative survey. Gen Hosp Psychiatry 2016;39:39-45. CrossRef

3. Kessler RC, Amminger GP, Aguilar-Gaxiola S, Alonso J, Lee S, Ustün TB. Age of onset of mental disorders: a review of recent literature. Curr Opin Psychiatry 2007;20:359-64. $\underline{\text { CrossRef }}$

4. Okruszek Ł, Aniszewska-Stańczuk A, Piejka A, Wiśniewska M, Żurek K. Safe but lonely? Loneliness, anxiety, and depression symptoms and COVID-19. Front Psychol 2020;11:579181. $\underline{\text { CrossRef }}$

5. Creese B, Khan Z, Henley W, et al. Loneliness, physical activity and mental health during COVID-19: a longitudinal analysis of depression and anxiety in adults over 5o between 2015 and 2020. Int Psychogeriatrics 2021;33:505-14. $\underline{\text { CrossRef }}$

6. van der Velden PG, Hyland P, Contino C, von Gaudecker HM, Muffels R, Das M. Anxiety and depression symptoms, the recovery from symptoms, and loneliness before and after the COVID-19 outbreak among the general population: findings from a Dutch population-based longitudinal study. PLoS One 2021;16:e0245057. CrossRef

7. Douglas PK, Douglas DB, Harrigan DC, Douglas KM. Preparing for pandemic influenza and its aftermath: mental health issues considered. Int J Emerg Ment Health 2009;11:137-44. PMID: 20437844

8. Talevi D, Socci V, Carai M, et al. Mental health outcomes of the CoViD-19 pandemic. Riv Psichiatr 2020; 55:137-44. CrossRef

9. Vindegaard N, Benros ME. COVID-19 pandemic and mental health consequences: systematic review of the current evidence. Brain Behav Immun 2020;89:53142. $\underline{\text { CrossRef }}$

10. Zhang Y, Ma ZF. Impact of the COVID-19 pandemic on mental health and quality of life among local resi- dents in Liaoning Province, China: a cross-sectional study. Int J Environ Res Public Health 2020; 17:2381. CrossRef

11. Torales J, O'Higgins M, Castaldelli-Maia JM, Ventriglio A. The outbreak of COVID-19 coronavirus and its impact on global mental health. Int J Soc Psychiatry 2020;66:317-20. CrossRef

12. Pfefferbaum B, North CS. Mental health and the Covid-19 pandemic. N Engl J Med 2020;383:510-12. CrossRef

13. Li W, Frank E, Zhao Z, et al. Mental health of young physicians in China during the novel coronavirus disease 2019 outbreak. JAMA Netw Open 2020; 3:e2010705. CrossRef

14. Löwe B, Wahl I, Rose M, et al. A 4-item measure of depression and anxiety: validation and standardization of the Patient Health Questionnaire-4 (PHQ4) in the general population. J Affect Disord 2010; 122:86-95.

15. Löwe B, Gräfe K, Zipfel S, et al. Detecting panic disorder in medical and psychosomatic outpatients: comparative validation of the Hospital Anxiety and Depression Scale, the Patient Health Questionnaire, a screening question, and physicians' diagnosis. J Psychosom Res 2003;55:515-19. CrossRef

16. Zhao SZ, Luk TT, Wu Y, et al. Factors associated with mental health symptoms during the COVID-19 pandemic in Hong Kong. Front Psychiatry 2021;12: 617397. $\underline{\text { CrossRef }}$

17. Mental Health Foundation (London, UK). Loneliness in young people: research briefing. 11 February 2021. Available at: https://www.mentalhealth.org.uk/ campaigns/unlock-loneliness/research-briefing (accessed August 6, 2021).

18. Lepper J. Rates of lockdown loneliness highest among young people. 8 April 2021. Children \& Young People Now. Available at: https://www.cypnow. co.uk/news/article/rates-of-lockdown-lonelinesshighest-among-young-people (accessed August 6, 2021). 